\title{
The Relationship Between Vision and Organizational Readiness for Change: The Mediating Effects of Empowerment and Trust in the Leader
}

\author{
MD Haque \\ University of La Verne
}

\author{
Lu Liu \\ University of La Verne
}

\author{
Angela Titi Amayah \\ California State University, Bakersfield
}

Purpose - The purpose of this paper is to investigate the relationship between vision and readiness for organizational change directly and through the mediating effects of empowerment and trust.

Design/methodology/approach - Data were collected from a sample of 409 managerial and nonmanagerial personnel from four business organizations. Structural equation modeling (SEM) was used to test direct and mediating effects.

Findings - Analyses provided strong support for the direct effects of vision and organizational readiness for change and the effects of vision on readiness for change were mediated by empowerment and trust in the leader.

Research limitations/implications - Vision is significantly associated with readiness for organizational change. However, both trust in leadership and sense of empowerment strengthen the relationship between the two variables.

Practical Implications - A compelling vision can improve employees' readiness for change by empowering them and by developing trust in the leader.

Originality/value -To the authors' knowledge, this is the first study to examine the mediating effects of trust and empowerment on the relationship between vision and organizational readiness for change.

Keywords: vision, empowerment, readiness for change, trust, vision and readiness for change 


\section{INTRODUCTION}

Research shows that articulation and communication of a vision for change is a primary mechanism for creating employees' readiness for organizational change (Armenakis et al.,-1993; Elias, 2009; Parish et al., 2008). Armenakis et al. (1999) noted that through the articulation of a vision, leaders inspire and create enthusiasm in individuals that they use to guide decisions about their level of support for the change initiative. The change literature has seemingly little empirical data to advance research and inform practitioners regarding the role of vision in creating readiness for change (Eby et al., 2000; Elias, 2009; Shah, 2010). The present study examined the extent to which readiness for organizational change is associated with vision.

According to Cole et al. (2006), readiness for change places demands on the individual employees to be psychologically ready. Although a few studies have identified several variables that may foster change readiness among employees (Bouckenooghe and Devos, 2007; Holt et al., 2007; Miller et al., 2006), none of these studies have investigated the potential psychological mechanisms through which those factors impact readiness for change (Choi, 2007). Research shows that empowerment generates a reciprocal response from the employees with relatively low levels of change readiness (Ahearne et al., 2005). Moreover, it's unclear whether employees' trust in their supervisors is a necessary condition for empowering leadership (Fineman, 2006). Taken together, as shown in figure 1, the purpose of this research project is to build a model that tests the relationship between vision and readiness for organizational change directly and through the mediating effects of factors such as empowerment and trust within the framework of structural equation modeling (SEM).

The theoretical framework for the study is consistent with transformational leadership theory, which states that employees are more likely to embrace change when a compelling vision for change is clearly articulated to them (Bommer et al., 2005; Wang et al., 2011). Moreover, vision motivates change among employees through the process of empowerment (Zaccaro and Banks, 2004). According to Spreitzer (1995), empowerment refers to a set of psychological states that are necessary for individuals to feel a sense of control in relation to their work. Similarly, consistent with transformational leadership theory, trust in leadership is likely to be associated with high levels of commitment to change (Bennis and Nanus, 1985; Michaelis et al., 2009). Trust in upper management is often evoked through open communication and disclosure conveyed in the vision for change (Byrne et al., 2005).

Although the authors are not aware of past research examining trust and empowerment in the leader as links between vision and readiness for organizational change, indirect support comes from studies using trust and empowerment to explain why certain leadership constructs are linked to important outcome variables. For instance, Zhu et al. (2013) found that trust in the leader explained the relationships of transformational leadership - in which vision is an integral part (Berson et al., 2015) - with higher level of organizational commitment for change. Similarly, Avolio et al. (2004) found that empowerment had an indirect mediating effect on the relationship between transformational leadership and organizational commitment for change. A study by Hoxha (2015) showed that vision, as a component of transformational leadership, is significantly related with trust and empowerment. The study also found that trust and empowerment predict higher levels of organizational effectiveness and they significantly mediate the relationship between transformational leadership and organizational effectiveness.

Responding to the call by Berson et al. (2001) to systematically examine the role of vision in organizational change, Haque et al. (2016) tested and found positive relationship between vision and its components, vision contents and attributes, and employee readiness for change. However, limited by a smaller sample size drawn from one organization, the study found positive relationship between vision attributes and readiness for change but failed to observe a significant association between vision content and readiness for change. Therefore, our intent in the current study is to draw from a larger sample size to retest the association among the variables. In addition, we added two important intervening variables, empowerment and trust, that have been idenfied as influencers (Berson et al., 2001) between vision in the context of change. To our knowledge, no studies have examined the role of empowerment and trust as mediators of the relationship between vision and readiness for organizational change. Consequently, the 
present study proposes that two intervening psychological processes are not only directly associated with readiness for change but they also mediate the relationship between vision and readiness for change.

This research not only contributes to filling the existing theoretical gap by examining the complex relationship between vision and employee readiness for change and the influence by two intervening variables, trust and empowerment, but also enriches the understanding of the organizational change process, and in turn enhance the ability to manage change.

This paper is organized as follows. First, the authors provide a brief review of the vision, readiness to change, trust and empowerment literature, followed by the development of our hypothesized model. Next, the population for the study, and the data collection and analysis process are discussed in the research methodology section. After a discussion of the findings, the implications of the study for theory and practice are discussed. The paper concludes with study limitations and suggestions for further research.

\section{LITERATURE REVIEW AND HYPOTHESIS DEVEOPMENT}

\section{Vision}

Pettigrew and Whipp (1991) found five factors that can explain the performance of companies: how firms assess their environment; how they lead change; how they link strategic and operational change; how they manage their human resources; and how they manage the coherence of the overall change process. In order to successfully lead change, scholars (i.e. Appelbaum, St-Pierre \& Glavas, 1998); Gilley, Gilley, \& McMillan, 2009; Kaplan \& Norton, 1996) suggest paying particular attention to the organization's vision, its clarity and communication to organizational members. As organizations have become more decentralized, there is a greater need for companies to also have a coherent, coordinated effort to achieve the company's objectives. The development of a shared vision is crucial to the achievement of this goal (Collins and Porras, 1991). Thus, changes routed in a clear vision should motivate members to follow that vision.

There are many different ways to define vision. James and Lahti (2011), for instance, defined vision as an idealized future state for the organization. According to others, vision is the essence of work (Tvorik and McGivern, 1997), future-oriented idealizations of shared organizational goals (Berson et al., 2016; Kirkpatrick and Locke, 1996; Kotter, 1995), among others. An organizational vision has three main purposes: (a) to inspire the organizational members (Almog-Bareket, 2011), (b) to provide a focus for employees' efforts and motivate them to accept and implement the organization's goals (Bennis and Nanus, 1985), and to create commitment to the desired future organizational state (Senge, 2006). In this study, the authors define vision as the idealized goal that represents or reflects a sense of direction that the leaders aspire for the organization (House and Shamir, 1993). The literature suggests two essential components of vision: vision attributes and vision content (Baum et al., 2001; Hickman, 2010; Kantabutra and Avery, 2009).

\section{Vision Attributes}

There are seven vision attributes that can be used to assess the effectiveness of an organizational vision (Baum et al., 1998, 2001; Kantabutra, 2009; Kantabutra and Avery, 2007). These attributes are brevity, clarity, abstractness, challenge, future orientation, stability, and desirability (Baum et al., 1998). Brevity is the extent to which a vision statement includes 11-22 words; clarity is the extent to which a vision emphasizes a primary goal to be achieved in a clearly determined time frame; abstractness refers to the fact that the vision reflects an idea the organization strives to achieve; challenge is the extent to which the vision motivates organization members to provide superior performance; future orientation is the extent to which a vision is forward looking; stability refers to the likelihood that the vision will not be affected by market and technology changes and desirability is the extent to which a vision specifies a goal and how that goal can benefit members (Kantabutra, 2009). 


\section{Vision Content}

Studies suggest that the content of a vision influences the extent to which the audience becomes inspired by, and committed to the vision (Awamleh and Gardner, 1999). Vision statements generally include three elements: goal orientation, how the firm plans to do business, and the type of environment organizational members will be working in (O'Brien and Meadows, 2003). It is also important that organizational members perceive the change to be appropriate (Armenakis et al., 1999). Appropriateness focuses on the possibility that individuals may accept a vision while disagreeing that a specific change is suitable to support that vision (Cole et al., 2006).

Kantabutra (2010b) noted that little research has been conducted into examining what constitutes an effective vision and how its components might simultaneously affect organizational change. Existing studies (i.e. Baum et al., 1998; Kantabutra, 2008, 2010a) found that vision content combined with the seven vision attributes are important to examine and enahance the effectiveness of the vision.

\section{Readiness for Change}

While there are many causes for failure of planned organizational change, a critical factor is the employees' attitudes towards the change. Several change experts argue that failure of change implementation is often due to employees not being ready for the change. According to Kotter (1996), for instance, about half of large scale organizational change efforts fail because organizational leaders neglect to get employees ready for the change or overestimate the extent to which they have prepared employees for change. Schein (1999) argued that the failure of organizational change initiatives could be linked to the organization's inability to create readiness for change before implementing the strategic vision. Given the frequency and complexity of changes in the workplace, resistance to change is the more common reaction (Turner Parish et al., 2008). As leaders and managers decide to implement change, they must consider not only the impact of the change on performance, but also how the change will affect employees. Organizational change is a perception-based construct that involves coordinated change at the individual level - organizations act and change through their members (Weiner et al., 2008).

Research on the change process is rooted in the work of Lewin's (1951), the famous three-stage model. According to Lewin (1951), during the first phase (unfreezing), organizational members become prepared for the change as the organization's leaders attempt to convince employees that the change is needed and will be successful; in the second phase (transforming), the change is implemented and employees adopt the new processes and the new strategic vision; finally, in the third phase (refreezing), the change is reinforced until it becomes the norm. Organizational readiness for change, which is similar to Lewin's concept of unfreezing, can be defined as "the extent to which organizational members are psychologically and behaviourally prepared to implement organizational change" (Weiner et al., 2008, p. 381).

Employees are not passive in the face of change (Choi and Ruona, 2011). Instead, they assess the change and determine whether they will be supportive of it. Therefore, it is important to the successful implementation of change efforts to create a readiness for change, build the ability to change, recruit support, communicate the need for change, and institutionalize the change (Almog-Bareket, 2011; Elias, 2009; Stevens, 2013). Additionally, a clear vision helps adaption to, and better success of organizational change (James and Lahti, 2011). Researchers have begun to focus on some of the variable that may improve employees' readiness for change, including existing organizational conditions and interpersonal dynamics (Armenakis et al., 1993). Prior research has shown that readiness for change is critical to the success of the change effort, and must occur before the organization starts implementing the change.

\section{Vision and Readiness for Change}

Based on the discussions above, it can be argued that individuals are more likely to support organizational change if they understand the need for change and the change coincides with the organization's overall strategic direction. Kotter (1995) have emphasized the importance of providing employees with a clear picture of what the organization is attempting to accomplish with the change strategy, and how the change supports the organization's long-term goals. He further noted, the vision 
should take into consideration the change need at every organizational level, so that the day-to-day work experience of the staff is described along with high-level change goals. Kantabutra (2010a) indicated that the seven attributes of vision are expected to improve the vision's effectiveness while acknowledging the fact that empirical research of vision attributes is virtually non-existent. In the same study, Kantabutra also noted that employees need to know the direction for change from the vision content before they agree with the vision and commit to it. Having showed the importance of vision attributes and vision content in creating change readiness, the following hypotheses were proposed:

\section{H1. Vision, characterized by vision attributes and content, is positively related to readiness for change.}

\section{Trust}

Trust is defined as belief in a person's dependability and integrity (Morgan and Hunt, 1994). Followers' trust was found in a number of studies to mediate the effectiveness of vision-based leadership (Jung and Avolio, 2000; Yukl, 1998). According to Yukl (1998), a leader's ability to build trust with followers will have a significant impact on a follower's commitment to his or her vision. Louis (2007) indicated that vision and its components provide a stimulus for changing perspectives among followers in a high trust organizational environment. However, they found vision to be ineffective in a low trust organizational environment and noted that even though although researchers tend to agree that trust is critical in determining the effects of leadership on followers, there is little empirical evidence to support the notion. Therefore, the study encouraged empirical work emphasizing on the intersection of leadership, trust and change.

Trust in management helps employees faced with organizational change accept the new vision (Rousseau and Tijoriwala, 1999). Employees with high levels of trust in organizational leaders are likely to be committed to the organization's strategies, to accept managers' justification for the change, support the change and believe it will be successful (Oreg et al., 2011; Rafferty and Simons, 2006; Turner Parish et al., 2008). During times of planned change, employees are likely to feel vulnerable to leaders' actions so the quality of the employment relationship will play an important role in employees' decision to support or not the change, and get involved (Rousseau and Tijoriwala, 1999). Rafferty and Simons (2006) suggest that trust in leaders increases readiness for change. Therefore, it is proposed that trust mediates the relationship between vision and readiness for change:

H2a. Trust is positively related to readiness for change.

H2b. The effect of vision, characterized by vision attributes and content, on readiness for change is partially mediated through trust.

\section{Empowerment}

When change is implemented, one of management's challenges is to empower employees in order to facilitate their engagement, and commitment to the organization. Empowerment enables individuals to make decisions. In practice, empowerment is getting rid of obstacles to change, removing or changing systems or structures that undermine the vision, and giving people the knowledge, opportunity, freedom, and self-confidence to manage themselves (Gill, 2003; Kotter, 1995). Empowerment is also about involving organizational members in the change process. People are more likely to support the new vision if they helped create it (Gill, 2003; Kopaneva and Sias, 2015). According to Kantabutra (2007), visionary leaders empower their people to act consistently with the new vision and to assist in sustaining their commitment to it. Transformational leadership theory suggests that employees who feel more empowered are more likely to reciprocate by being more committed to the organization's change (Avolio et al., 2004). Kantabutra (2010a) advanced a proposition drawing connections between vision and empowerment. The autor also indicated that empowered employees tend to be more supportive of accomplishment of vision. In the context of the present study, this implies creating readiness for change. between Based on the above arguments, it is hypothesize that:

Journal of Organizational Psychology Vol. 20(2) 2020163 
H3a. Empowerment is positively related to readiness for change.

H3b. The effect of vision, characterized by vision attributes and content, on readiness for change is partially mediated through empowerment.

\section{METHOD}

\section{Participants and Procedures}

Participants in the current study were employed by four business organizations from the Western United States. Of the four organizations, two were information and communication technology (ICT) companies, the third was a business consulting company, and the last was a parking management company. All four organizations had written vision statements and they had experienced recent organizational changes, including major reorganization efforts and downsizing, changes in top management, mergers and acquisitions, and business divestments. High degrees of change taking place in these organizations provided a useful context for studying the readiness for change.

Each organization was asked to identify a random sample of all employees who would serve as participants. In total, 550 managerial and non-managerial employees from the four organizations were selected for participation in the study. Recruitment e-mails containing information about the study and the link to an online survey were sent to all selected participants. Subjects were assured of the anonymity of their response. A total of 409 respondents completed the survey, out of which $45 \%$ are male and $55 \%$ are female. The majority of the sample was white $(73.6 \%)$, with $11.8 \%$ Asian, $7.5 \%$ Hispanic, 3\% black, $1.2 \%$ Native American, and the rest not reporting ethnicity. About one third of the participants are from the 41-50 years old age group, and 20\% each from the 31-40 years old age group and the 51-60 years old age group. Also, about $65 \%$ of the participants had a Bachelor's or higher degree and held middle to senior leadership positions. About $76.7 \%$ of the subjects have been working with their present organization for six years or more. It is important to note that by using different sources of data collection we reduced potential for common method variance bias (Podsakoff, MacKenzie, Lee, \& Podsakoff, 2003).

\section{Measures}

Vision was assessed by two seven-point Likert scales developed by Baum et al. (1998): vision attributes and vision content. Vision attributes measure seven attributes (brevity, clarity, abstractness, challenge, future orientation, stability, and desirability or ability to inspire), while vision content measures the extent to which the contents of a vision involve an organization's high growth of profits, sales, employment, facilities, market share, financial strength, or product offerings. One of the items to measure vision content was "Does/did it refer to high growth in profits", whereas the question to measure vision attributes for clarity was "Is/was it's meaning clear and easily understandable". The reliability estimate of the vision attributes scale was 0.96 and 0.88 for the vision content scale (Baum et al., 1998).

Trust was measured using three questions. The questions asked the manager can always be trusted, can be trusted completely, and can be counted on to do what is right. The scale was originally developed by Morgan and Hunt (1994) and modified by Parish et al. (2007). In this study, the modified version of the survey was used. One of the items to measure vision content was "My managers can always be trusted." The reliability estimate of the items was 0.98 (Parish et al., 2007).

Employee perceptions of empowerment were assessed using a 12-item empowerment scale developed by Spreitzer (1995). The items measure employees' assessments of the extent to which they derive meaning, self-determination, competency and impact from their assigned tasks and work context. The questions to measure empowerment include "I have significant autonomy in determining how I do my job" and "I have considerable opportunity for independence and freedom in how I do my job". The reliability estimate of this scale is reported to be 0.74 (Spreitzer, 1995).

Readiness for change was measured using 18-item scale developed by Dunham et al. (1989) that assesses the degree to which participants have positive feelings (e.g. "I find most change to be pleasing"), 
thoughts (e.g. "Change usually helps improve unsatisfactory situations at work") and behavioral intentions (e.g. "I intend to do whatever possible to support change") toward change in the organization. The reliability estimate of this scale is reported to be 0.89 .

\section{Data Analysis}

Once the data preparation and screening processes were complete, data analysis first focused on the descriptive statistics of the variables of interest, that is, the average scores in the whole sample. Next, using the confirmatory factor analysis (CFA), two-step identification rule as laid out by Bollen (1989) and Kline (2016) was followed to identify and evaluate the fit of the model. Besides the above overall goodness of fit indices, localized areas of strain such as residuals and modification indices and the interpretability of the parameter estimates were assessed for the measurement model as well. See Figure 1 for the model testing results and the standardized parameter estimates.

Hypotheses for the study were tested using structural equation modeling (SEM) techniques in the statistical software Mplus. One advantage of MPLUS is that it provides tests of significance for indirect or meditational effects (Muthen \& Muthen, 2012). SEM is known for its ability to model latent variables and explore complex relationships among a set of variables (Kelloway, 2015). For example, a sample size of 100 to 200 is the least requirement for models with latent variables (Marsh et al., 1988). SEM can analyze hypothesized relationships among latent and observed variables, which can serve as independent, control, mediator or dependent variables in the same model.

\section{RESULTS}

\section{Measurement Model}

Based on the past literature, six indicators were specified to load on the empowerment factor and six indicators were specified to load on the readiness for change factor. The initial results revealed good overall model fit but with fairly large standard residuals $(>2.58)$ and modification indices $(>10.0)$ for two indictors, one for empowerment "My impact on what happens in my department is large" and one for readiness for change "Other people think that I support change". Considering the weak factor loading $(<0.4)$ of each item on its respective factor, the two indicators were dropped from the factor analysis. The final measurement model fits the data well: $X^{2}(34)=34.880, p=0.426$, SRMR $=0.025$, RMSEA $=0.008$ $(90 \% \mathrm{CI}=0.00-0.037, \mathrm{Cfit}=0.99), \mathrm{TLI}=0.999, \mathrm{CFI}=0.999$. Inspection of standardized residuals and modification indices suggested no localized points of ill fit in the solution either. The largest modification index is below 5.0 and the largest standardized residual is below 2.58 as well. All freely estimated unstandardized parameters were statistically significant $(p s<0.001)$ and the factor loading estimates revealed that the indicators were strongly related to their underlying factors $(>0.6)$. In the meantime, although there was a high moderate relationship between empowerment and readiness for change in the two-factor solution (0.744), it's still lower than the cutoff criterion of 0.85 for problematic discriminant validity (Cohen et al., 2003; Tabachnick and Fidell, 2013).

\section{Hypotheses Testing}

Built upon the measurement model, the fit indices for the structural model provided evidence for a good model: $X^{2}(58)=64.638, p=0.256$, SRMR $=0.024, \mathrm{RMSEA}=0.017(90 \% \mathrm{CI}=0.00-0.036$, Cfit $=0.99)$, $\mathrm{TLI}=0.995, \mathrm{CFI}=0.996, \mathrm{AIC}=12985.601$, and $\mathrm{BIC}=13150.163$. Thus, the model fit the data well. The detailed results for each hypothesis are listed as follows.

For hypothesis 1 , both vision attributes and vision content are positively related to readiness for change. Both vision attributes and vision content have a direct impact on readiness for change $(\beta=0.312$, $\mathrm{p}<0.001$ and $\beta=0.361, \mathrm{p}<0.001$ ). 
TABLE 1

STANDARDIZED TOTAL, TOTAL INDIRECT, SPECIFIC INDIRECT, AND DIRECT EFFECTS FROM VISION ATTRIBUTES (VA) AND VISION CONTENT (VC) TO READINESS FOR CHANGE (CHANGE)

\begin{tabular}{|c|c|c|c|c|c|}
\hline & & Estimate & S.E. & Est./S.E. & P-Value \\
\hline \multicolumn{6}{|c|}{ VA to Change } \\
\hline & Direct & 0.312 & 0.047 & 6.598 & $0.000 * * *$ \\
\hline & Indirect & 0.125 & 0.026 & 4.782 & $0.000 * * *$ \\
\hline & $\rightarrow$ Trust & 0.032 & 0.014 & 2.309 & $0.021 * *$ \\
\hline & $\rightarrow$ Empower & 0.062 & 0.025 & 2.414 & $0.016 * *$ \\
\hline & $\rightarrow$ Empower+Trust & 0.032 & 0.010 & 3.216 & $0.001 * * *$ \\
\hline & Total & 0.438 & 0.044 & 9.992 & $0.000 * * *$ \\
\hline \multicolumn{6}{|c|}{ VC to Change } \\
\hline & Direct & 0.361 & 0.050 & 7.164 & $0.000 * * *$ \\
\hline & Indirect & 0.185 & 0.031 & 5.911 & $0.000 * * *$ \\
\hline & $\rightarrow$ Trust & 0.072 & 0.021 & 3.468 & $0.001 * * *$ \\
\hline & $\rightarrow$ Empower & 0.074 & 0.030 & 2.478 & $0.013 * *$ \\
\hline & $\rightarrow$ Empower+Trust & 0.039 & 0.011 & 3.371 & $0.001 * * *$ \\
\hline & Total & 0.546 & 0.042 & 12.880 & $0.000 * * *$ \\
\hline
\end{tabular}

For hypothesis 2(a), trust is positively related to readiness for change. Trust has a significant direct impact on readiness for change $(\beta=0.233, p<0.001)$.

For hypothesis $2(\mathrm{~b})$, the effect of vision on readiness for change is partially mediated through trust. There is significant indirect effect from vision attributes to readiness for change mediated through trust $(\beta=0.032, \mathrm{p}<0.05)$ and significant indirect effect from vision content to readiness for change mediated through trust $(\beta=0.072, \mathrm{p}<0.05)$.

For hypothesis 3(a), empowerment is positively related to readiness for change. Empowerment has a significant direct impact on readiness for change $(\beta=0.178, \mathrm{p}<0.05)$.

For hypothesis $3(\mathrm{~b})$, the effect of vision on readiness for change is partially mediated through empowerment. There is a significant indirect effect from vision attributes to readiness for change mediated through empowerment $(\beta=0.062, p<0.05)$ and significant indirect effect from vision content to readiness for change mediated through empowerment $(\beta=0.074, p<0.05)$. There is also a significant indirect effect from vision attributes to readiness for change mediated through both empowerment and trust $(\beta=0.032, p<0.001)$ and significant indirect effect from vision content to readiness for change mediated through both empowerment and trust $(\beta=0.039, \mathrm{p}<0.001)$. Together the total indirect effect from vision attributes to readiness for change is $0.125(\mathrm{P}<0.001)$ and the total indirect effect from vision content to readiness for change is $0.185(\mathrm{P}<0.001)$.

\section{DISCUSSION}

Although vision is widely considered important in the context of organizational change (Kotter, 1990; House and Shamir, 1993), only one study examined the direct association between vision and organizational readiness for change (Haque et al., 2016) and the two psychological factors - trust in leadership and empowerment - as predictors to readiness for change and as mediators to the relationship between the vision and readiness for change.

Our findings suggest three main conclusions. First, the authors found that vision attributes and vision content, two essential components of vision, are significantly related to readiness for change. This supports the assumptions that vision and readiness for change are related (McKay et al., 2013). While a 
previous study by Haque et al. (2016) found that only vision attributes is significantly related to readiness for change, the results from the present study suggest that both vision attributes and content are significantly related to readiness for change. The finding emphasizes that developing a vision for the future helps facilitate organizational change (Gill, 2003), as vision clarifies the direction for change and motivates employees to buy into the change process (Kotter, 1997). Previous research, for example Nemanich and Keller (2007) indicates a positive relationship between leader vision and success of organizational change efforts such as mergers and acquisitions. Our findings ameliorate the understanding of the impact of the leader's vision in the context of change readiness.

Second, consistent with previous studies, trust (Faghihi and Allameh, 2012; Mangundjaya, 2015; Zayim and Kondakci, 2015) and empowerment (Lizar et al., 2015) were found directly influence readiness for change. In addition, the study provided empirical evidence that trust in the leader and psychological empowerment mediated the relationship between leaders' vision and employees' readiness for change. These results suggest that through trust and empowerment, vision for change characterized by vision attributes and content increases the employee readiness for change. The findings are consistent with those in previous studies (Dirks and Ferrin, 2002; Goodwin et al., 2011; Morgan and Zeffane, 2003) that employee empowerment and trust in leaders often lead to greater support from employees for change. Our findings also indicate that trust may emerge as a belief in the positive vision of organizational leaders (Foster-Fishman and Keys, 1997), which helps connect employees with the organization and increase their willingness to support change (Weick, 1985). Moreover, the finding provides empirical support for the notion that a clear and meaningful vision for change is likely to increase followers' psychological empowerment and motivate them act on the vision (Kantabutra, 2010a; Kotter, 1995). These findings conincide with previous studies that articulation of a viable vision by leaders was related to a variety of outcomes including follower satisfaction, motivation, and performance (Partlow et al., 2015). Moreover, the outcome of the study provides empirical support to the conceptual connections advanced by researchers that the components of vision attributes (e.g. Kantabutra, 2010a) and vision content (Berson et al., 2001) can contribute to trust bullding and empowerment.

Third, the study provided empirical evidence that trust and empowerment reinforce each other and together lead to enhancement of readiness for change. While it was not a part of the theoretical model tested in this study, the finding indicates that empowerment of followers is related to trust in leader. This finding is consistent with previous studies (Douglas and Zivnuska, 2008; Louis, 2007). Louis (2007) claimed that sense of empowerment such as perceived influence over decision making could be a significant enhancer of trust. Similarly, a study by Laschinger and Finegan (2005) found a positive relationship between empowerment and trust. The authors went on to note that an empowering environment and a climate of trust would indicate a highler level of commitment to the organization. In the current study, the commitment has been validated in the context of change.

Finally, the study empirically substantiated and extended theoretical propositions such as the conceptual work by Kantabutra (2010a) and empirical findings such as the empirical work by Baum et al. (1998). The main goal of this study was to expand upon previous research in regards to the relationships between vision and organizational readiness for change. However, the uniqueness of this study was to examine whether mediating variables such as trust in leadership and empowerment enhanced the relationship between vision for change and organizational leadership for change. In conclusion, our study shows that a more complete understanding of what drives employee readiness for change may need to focus on a vision that promotes empowerment and enhances trust in top management.

\section{IMPLICATIONS}

The present results suggest implications for future research and practice. First, since our results suggest that the seven vision attributes and vision content have direct and indirect effects on change readiness among employees, this should inspire leaders to introduce change by defining and articulating a compelling vision. In line with previous inquiries on vision content, findings from our study highlight the importance of vision content (i.e. Berson et al., 2001) and vision attributes (Kantabutra, 2010a) in 
promoting organizational change. Awamleh and Gardner (1999) found that leaders can be taught to articulate and communicate their visions effectively. Therefore, it would be valuable for leadership development programs to emphasize on creating and articulating effective visions as an important aspect of leading change. While there is no one formula to develop a vision, the study found that vision attributes (Baum et al. 1998) and a well-articulated vision content seem to provide useful guidance.

Second, leaders should exhibit confidence in subordinates, create a supportive environment, allow opportunities for employees to participate in change related decision-making process and provide greater autonomy to ensure that the employees felt empowered (Kantabutra 2008, 2010a). By creating a greater sense of empowerment, leaders may have a more positive effect on levels of readiness for change among employees. To promote greater feelings of empowerment, leaders should clearly articulate a vision for change that inspires followers to engage in the change process. Our findings also show that when employees feel empowered, they tend to develop trust in their leaders.

Third, our results emphasize the importance of trust building in organizational change readiness process. To begin with, leaders need to make efforts to establishing trust in the relationship with the employees (Baker et al., 2015). Moreover, it is important to note that a well-articulated compelling vision positively influences trust among employees. Organizations can benefit greatly by providing training to their leaders to enhance followers' trust in the leader and empowerment (Berson et al., 2016), which in turn enhance employee readiness for change.

\section{LIMITATIONS AND RECOMMENDATIONS FOR FUTURE RESEARCH}

Our study is not free of limitations that should be kept in mind when interpreting the findings. First, this is one of the first studies explicitly combining vision and readiness for change with mediating processes via trust in the supervisor and empowerment. Although vision significantly contributes to the readiness for change, in reality there are more factors to consider that might affect employee readiness and commitment to change. Thereby, the following were not included in the study: (a) other forms of leadership components, (b) additional mediators, and (c) potential downsides to the proposed relationships. The authors encourage researchers to further validate and extend our model by including other relevant variables.

Second, one of the main weaknesses of this study was the use of a cross-sectional design, which does not allow for an assessment of impact or cause and effect. Thus, the study could not test whether vision causes feelings of empowerment and trust, nor could it test whether trust and empowerment positively causes higher levels of organizational readiness for change. The authors encourage future research to incorporate data at different time points for longitudinal analyses to infer causation.

Third, research shows trust in the supervisor is sensitive to cultural differences (Casimir et al., 2006). Our research within a single cultural context does not allow any test of the causative influence of the context. Thus, it could be enlightening to further test the differential effects of trust in the supervisor in other cultures. Future research should therefore include samples from multiple cultures that differ on theoretically critical cultural values

\section{CONTRIBUTIONS OF THE STUDY}

Despite the stated limitations, our study makes several substantial contributions to research on leadership and organizational change. First, consistent with the suggestion by Lizar et al. (2015), the study empirically examined a robust model explaining a direct relationship between leadership vision and readiness for change as well as indirect relationship between the two variables through empowerment and trust.

Second, scholars emphasized the importance of a vision in creating readiness for organizational change (Armenakis et al., 1993; Kotter, 1995). These authors suggest that a vision should be persuasive and meaningful, demonstrating change appropriateness and effective execution. Our study supports vision 
theory by Baum et al. (1998), as vision characterized by brevity, clarity, abstractness, challenge, future orientation, stability, and desirability as well as the vision content were related to readiness for change.

Third, there is consensus among academics that leaders often need to gain the support of employees to help implement the change. Studies show that leaders attempt to gain the employee support for change by making them feel empowered (Detert and Burris, 2007). This study found that empowerment is associated with readiness for change. The study also found that empowerment has a positive relationship with trust, consistent with Schweiger and DeNisi (1991), and trust is related to organizational readiness for change.

In conclusion, this is the first study to examine the mediating effects of trust and empowerment on the relationship between leadership vision and organizational readiness for change. It is suggested that organizations implementing change should take into account the findings of the present study and attempt to address the role of vision in organizational readiness for change and the mediating role of psychological constructs such as trust and empowerment. 


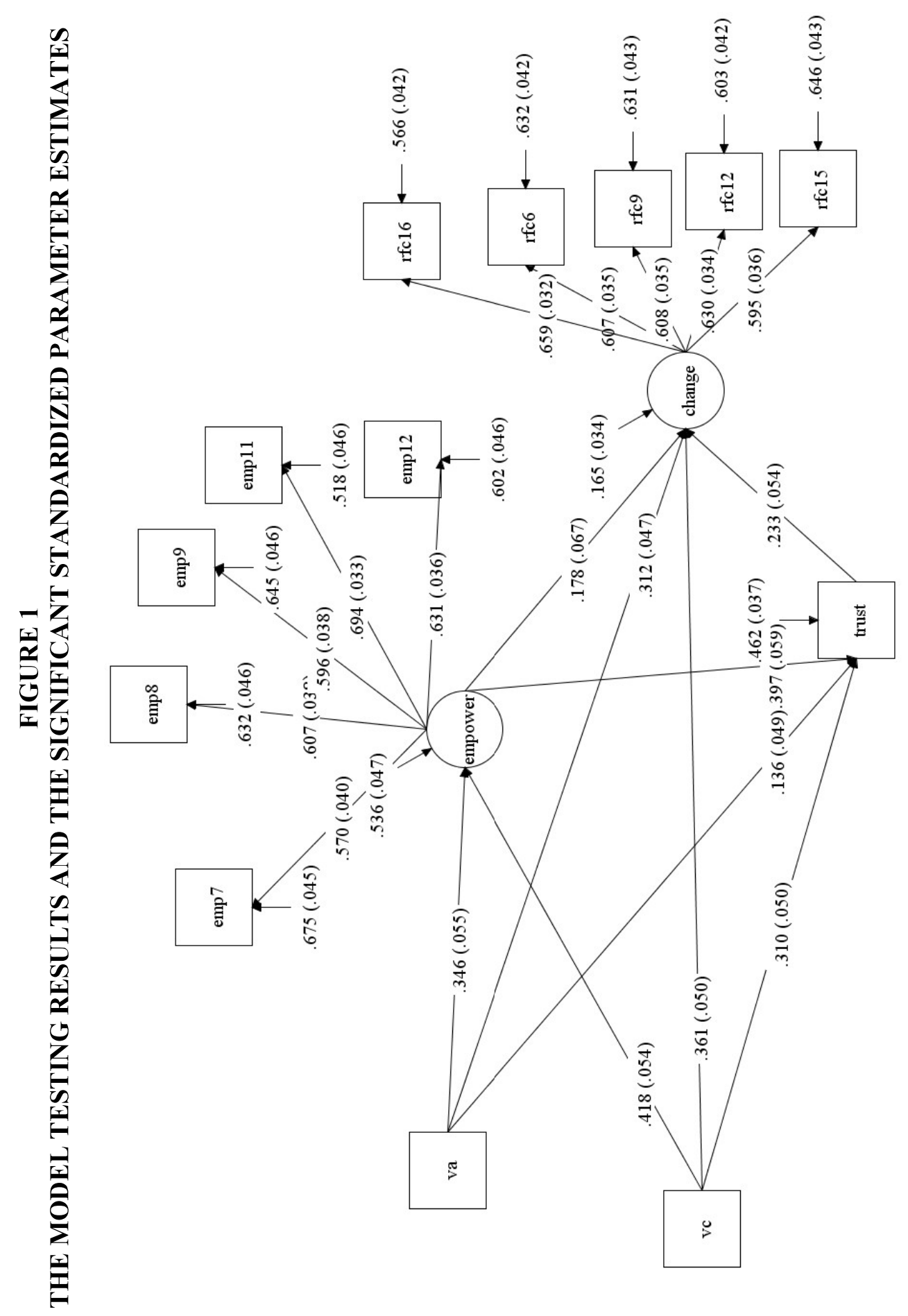

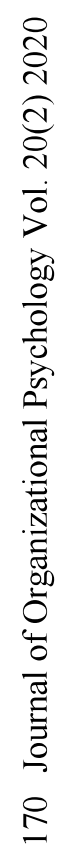




\section{REFERENCES}

Almog-Bareket, G. (2011). The missing component in MBA programs. Management Decision, 49(10), 1600-1611.

Appelbaum, S., St-Pierre, N., \& Glavas, W. (1998). Strategic organizational change: The role of leadership, learning, motivation and productivity. Management Decision, 36(5), 289-301.

Armenakis, A.A., Harris, S.G., \& Mossholder, K.W. (1993). Creating readiness for organizational change. Human Relations, 46(6), 681-703.

Armenakis, A. A., \& Bedeian, A. G. (1999). Organizational change: A review of theory and research in the 1990s. Journal of Management, 25(3), 293-315.

Avolio, B. J., Weichun, Z., Koh, W., \& Bhatia, P. (2004). Transformational leadership and organizational commitment: mediating role of psychological empowerment and moderating role of structural distance. Journal Of Organizational Behavior, 25(8), 951-968. doi:10.1002/job.283.

Awamleh, R., \& Gardner, W. L., (1999). Perceptions of leader charisma and effectiveness: The effects of vision content, delivery, and organizational performance. The Leadership Quarterly, 10(3), 345373.

Baker, S. D., Mathis, C. J., Stites-Doe, S., \& Javadian, G. (2016). The Role of Trust and Communication in Fostering Followers' Self Perceptions as Leaders. Journal Of Managerial Issues, 28(3/4), 210 230.

Baum, J.R., Locke, E.A., \& Kirkpatrick, S.A. (1998). A longitudinal study of the relation of vision and vision communication to venture growth in entrepreneurial firms. Journal of Applied Psychology, 83(1), 43-54.

Baum, J.R., Locke, E.A., \& Smith, K.G. (2001). A multidimensional model of venture growth. Academy of Management Journal, 44(2), 292-303.

Bennis, W.G., \& Nanus, B. (1985). Leaders: The Strategies for Taking Charge. Harper Collins, New York, NY.

Berson, Y., Waldman, D. A., \& Pearce, C. L. (2016). Enhancing our understanding of vision in organizations: Toward an integration of leader and follower processes. Organizational Psychology Review, 6(2), 171-191.

Berson, Y., Halevy, N., Erez, M., \& Shamir, B. (2015). Leading From Different Psychological Distances: A Construal-Level Perspective on Vision Communication, Goal Setting, and Follower Motivation. Leadership Quarterly, 26(2), 143-155.

Berson, Y., Shamir, B., Avolio, B. J., \& Popper, M. (2001). The relationship between vision strength, leadership style, and context. The Leadership Quarterly, 12(1), 53-73.

Casimir, G., Waldman, D. A., Bartran, T., \& Yang, S. (2006). Trust and the relationship between leadership and follower performance: Opening the black box in Australia and China. Journal of Leadership and Organizational Studies, 12, 68-84.

Choi, M., \& Ruona, W.E.A. (2011). Individual readiness for organizational change and its implications for human resource and organization development. Human Resource Development Review, 10(1), 46-73.

Cole, M.S., Harris, S.G., \& Bernerth, J.B. (2006). Exploring the implications of vision, appropriateness, and execution of organizational change. Leadership \& Organization Development Journal, 27(5), 352-367. doi: 10.1108/01437730610677963

Collins, J.C., \& Porras, J.I. (1991). Organizational vision and visionary organizations. California Management Review, 34(1), 30-52.

Dirks, K. T., \& Ferrin, D. L. (2002). Trust in leadership: meta-analytic findings and implications for research and practice. Journal of applied psychology, 87(4), 611-628.

Douglas, C., \& Zivnuska, S. (2008). Developing Trust in Leaders: An Antecedent of Firm Performance. S.A.M. Advanced Management Journal, 73(1), 20-28. 
Dunham, R. B., Grube, J. A., Gardner, D. G., Cummings, L. L., \& Pierce, J. L. (1989, August). The development of an attitude toward change instrument. In Academy of Management annual meeting. Washington, DC.

Eby, L.T., Adams, D.M., Russell, J.E.A., \& Gaby, S.H. (2000). Perceptions of organizational readiness for change: factor related to employees' reactions to the implementation of team-based selling. Human Relations, 53(3), 419-442.

Elias, S. M. (2009). Employee commitment in times of change: assessing the importance of attitudes toward organizational change. Journal of Management, 35(1), 37-55. doi: $10.1177 / 0149206307308910$

Faghihi, A., \& Allameh, S. M. (2012). Investigating the influence of employee attitude toward change and leadership style on change readiness by SEM. International Journal of Academic Research in Business and Social Sciences, 2(11), 215-227.

Foster-Fishman, P. G., \& Keys, C. B. (1997). The person/environment dynamics of employee empowerment: An organizational culture analysis. American Journal of Community Psychology, 25(3), 345-369.

Gill, R. (2003). Change management--or change leadership? Journal Of Change Management, 3(4), 307318.

Gilley, A., Gilley, J. W., \& McMillan, H. S. (2009). Organizational change: Motivation, communication, and leadership effectiveness. Performance Improvement Quarterly, 21(4), 75-94.

Goodwin, V., Whittington, L., Murray, B., \& Nichols, T. (2011). Moderator or mediator? Examining the Role of Trust in the Transformational Leadership Paradigm. Journal of Managerial Issues, 23(4), 409-425

Haque, M., Titi Amayah, A., \& Liu, L. (2015). The role of vision in organizational readiness for change. Leadership and Organizational Development Journal. In press.

Hickman, G.R. (2010). Organizational Change Practices. In G.R. Hickman (Ed.), Leading Organizations: Perspectives for a New Era (2nd ed., pp. 510-524). Sage, Los Angeles, CA.

House, R.J., \& Shamir, B. (1993). Toward the integration of transformational, charismatic and visionary theories of leadership. In M.M. Chemers \& R. Ayman (Eds.), Leadership Theory and Research: Perspectives and Directions (pp. 81-107). Academic Press, San Diego, CA.

Hoxha, A. (2015). Empowerment and trust as mediators of the relationship between transformational leadership and organizational effectiveness. European Journal of Economic and Political Studies, 8(1), 43-60.

James, K., \& Lahti, K. (2011). Organizational vision and system influences on employee inspiration and organizational performance. Creativity and Innovation Management, 20(2), 108-120.

Jung, D.I., \& Avolio, B. J. (2000). Opening the black box: An experimental investigation of the mediating effects of trust and value. Journal Of Organizational Behavior, 21(8), 949-964.

Kantabutra, S. (2010a). Vision effects: A critical gap in educational leadership research. The International Journal of Educational Management, 24(5), 376-390.

Kantabutra, S. (2010b). Negative vision effect in Thai retail stores. Singapore Management Review, 32(1), 1-28.

Kantabutra, S. (2009). Toward a behavioral theory of vision in organizational settings. Leadership \& Organization Development Journal, 30(4), 319-337.

Kantabutra, S., \& Avery, G.C. (2009). Shared vision in customer and staff satisfaction: Relationships and their consequences. Journal of Applied Business Research, 25(4), 9-21.

Kantabutra, S. (2008). Vision effects in Thai retail stores: practical implications. International Journal of Retail \& Distribution Management, 36(4), 323-342.

Kantabutra, S., \& Avery, G.C. (2007). Vision effects in customer and staff satisfaction: an empirical investigation. Leadership \& Organization Development Journal, 28(3), 209-229.

Kaplan, R.S., \& Norton, D.P. (1996). Using the balanced scorecard as a strategic management system. Harvard Business Review, 74(1), 75-85.

172 Journal of Organizational Psychology Vol. 20(2) 2020 
Kirkpatrick, S.A., \& Locke, E.A. (1996). Direct and indirect effects of three core charismatic leadership components on performance and attitudes. Journal of Applied Psychology, 81(1), 36-51. doi: $10.1037 / 0021-9010.81 .1 .36$

Kopaneva, I., \& Sias, P. M. (2015). Lost in translation: Employee and organizational constructions of mission and vision. Management Communication Quarterly, 29(3), 358-384.

Kotter, J.P. (1997). Leading by Vision and Strategy. Executive Excellence, 14(10), 15-16.

Kotter, J.P. (1995, March-April). Leading change: why transformation efforts fail. Harvard Business Review, 73, 59-67.

Kotter, J.P. (1996). Leading Change. Harvard Business Press, Boston, MA.

Laschinger, H., \& Finegan, J. (2005). Using empowerment to build trust and respect in the workplace: a strategy for addressing the nursing shortage. Nursing Economics, 23(1), 6-13.

Ledford, G.E., Jr., Wendenhof, J.R., \& Strahley, J.T. (1995). Realizing a corporate philosophy. Organizational Dynamics, 23(3), 4-19.

Lewin, K. (1951). Field Theory in Social Science: Selected Theoretical Papers. Harper, New York, NY.

Lizar, A. A., Mangundjaya, W. L., \& Rachmawan, A. (2015). The Role of Psychological Capital and Psychological Empowerment on Individual Readiness for Change. The Journal of Developing Areas, 49(5), 343-352.

Louis, K. S. (2007). Trust and improvement in schools. Journal of educational change, 8(1), 1-24.

Mangundjaya, W. L. (2015). People or Trust in Building Commitment to Change? The Journal of Developing Areas, 49(5), 67-78.

Morgan, D. E., \& Zeffane, R. (2003). Employee involvement, organizational change and trust in management. International Journal of Human Resource Management, 14(1), 55-75.

Morgan, R.M., \& Hunt, S.D. (1994). The commitment-trust theory of relationship marketing. Journal of Marketing, 58(3), 20-38.

Muthen, L. K., \& Muthen, B. (2012). 1998-2012. Mplus User's Guide. Muthen \& Muthen, Los Angeles, CA.

Nemanich, L. A., \& Keller, R. T. (2007). Transformational leadership in an acquisition: A field study of employees. The Leadership Quarterly, 18(1), 49-68.

O'Brien, F., \& Meadows, M. (2003). Exploring the current practice of visioning: case studies from the UK financial services sector. Management Decision, 41(5), 488-497.

Oreg, S., Vakola, M., \& Armenakis, A. (2011). Change recipients' reactions to organizational change: A 60 -year review of quantitative studies. The Journal of Applied Behavioral Science, 47(4), 461524.

Partlow, P. J., Medeiros, K. E., \& Mumford, M. D. (2015). Leader cognition in vision formation: Simplicity and negativity. The Leadership Quarterly, 26(3), 448-469.

Paton, R.A., \& McCalman, J. (2000), Change Management: A Guide to Effective Implementation. Sage, London.

Pettigrew, A., \& Whipp, R. (1991). Managing Change for Competitive Success. Basil Blackwell, Oxford.

Podsakoff, P., MacKenzie, S., Lee, J., \& Podsakoff, N. (2003). Common method biases in behavioral research: a critical review of the literature and recommendation remedies. Journal of Applied Psychology, 88, 879-903.

Rafferty, A., \& Simons, R. (2006). An examination of the antecedents of readiness for fine-tuning and corporate transformation changes. Journal of Business \& Psychology, 20(3), 325-350.

Rousseau, D.M., \& Tijoriwala, S.A. (1999). What's a good reason to change? Motivated reasoning and social accounts in promoting organizational change. Journal of Applied Psychology, 84, 514-28

Schein, E. H. (1999). Process Consultation Revisited: Building the Helping Relationship. AddisonWesley, Reading, MA.

Schweiger, D. M., \& Denisi, A. S. (1991). Communication with employees following a merger: A longitudinal field experiment. Academy of Management Journal, 34(1), 110-135.

Senge, P. (2006). Shared vision. In P. Senge (Ed.), The Fifth Discipline: The Art and Practice of the Learning Organization (pp. 205-232). Bantam-Doubleday, New York, NY. 
Shah, N. (2010). A study of the relationship between organisational justice and employee readiness for change. Journal of Enterprise Information Management, 24(3), 224-236.

Stevens, G.W. (2013). Toward a process-based approach of conceptualizing change readiness. The Journal of Applied Behavioral Science, 49(3), 333-360.

Turner Parish, J., Cadwallader, S., \& Busch, P. (2008). Want to, need to, ought to: employee commitment to organizational change. Journal of Organizational Change Management, 21(1), 32-52.

Tvorik, S.J., \& McGivern, M.H. (1997). Determinants of organizational performance. Management Decision, 35(6), 417-435.

Wang, G., Oh, I-S., Courtright, S. H., \& Colbert, A. E. (2011). Transformational leadership and performance across criteria and levels: A meta-analytic review of 25 years of research. Group \& Organization Management, 36(2), 223-270.

Weick, K. (1984). Small wins: Redefining the scale of social problems. American Psychologist, 39(1), 40-49.

Weiner, B., Amick, H., \& Lee, S.Y. (2008). Conceptualization and measurement of organizational readiness for change: A review of the literature in health services research and other fields. Medical Care Research and Review, 65(4), 379-436.

Yukl, G. A. (1998). Leadership in organizations. Prentice Hall, Englewood Cliffs, NJ.

Zayim, M., \& Kondakci, Y. (2015). An exploration of the relationship between readiness for change and organizational trust in Turkish public schools. Educational Management Administration \& Leadership, 43(4), 610-625. 